EESTI NSV TEADUSTE AKADEEMIA TOIMETISED 26. KOIDE

KEEMIA * GEOLOOGIA. 1977, Nr. 3

НЗВЕСТИЯ АКАДЕМИИ НАУК ЭСТОНСКОИ ССР. ТОМ 26

ХИМИЯ * ГЕОЛОГИЯ. 1977, № 3

удк 547.461

Сибилле МУЭЛЛЕР, А. МЯНННК, А. ФОМННА, А. КУЦЕНКО, Г. ЛЫСЕНКО

\title{
ПЕРЕЭТЕРИФИКАЦИЯ ДИМЕТИЛАДИПАТА 2-ЭТИЛ ГЕКСАНОЛОМ
}

Распространенным способом разделения смесей насыщенных дикарбоновых кислот является этерификация их метиловым спиртом и ректификация продуктов метилирования. Полученные сложные эфиры обычно представляют собой лишь промежуточный продукт для последующих процессов гидролиза и кристаллизации. Целью настоящей работы было исследование реакционной способности диметиловых эфиров дикарбоновых кислот (ДМЭ ДКК) как исходного сырья для получения диалкиловых эфиров переэтерификацией высокомолекулярными спиртами.

Несмотря на то что диалкиловые эфиры дикарбоновых кислот широко используются в качестве пластификаторов и смазочных масел, в литературе имеются лишь некоторые данные о закономерностях реакции переэтерификации диметиловых эфиров ароматических дикарбоновых кислот $[1,2]$ и практически отсутствуют они о переэтерификации насыщенных алифатических дикарбоновых кислот. Последнее обстоятельство обусловлено, по-видимому, трудностями точного количественного определения продуктов реакции. В целях преодоления этих трудностей разработан газохроматографический метод одновременного количественного определения исходных, промежуточных и конечных продуктов реакции переэтерификации. Для этого использовался хроматограф «Хром-4» с пламенно-ионизационным детектором (диаметр колонки 3 мм, длина ее 90 cм, твердый носитель - хромосорб $W$ (60-80 меш.); жидкая фаза ПЭГА $0,4 \%$ от веса твердой фазы; газ-носитель-аргон). Температура колонки программировалась от 120 до $230^{\circ} \mathrm{C}$; количество вводимой пробы составляло 0,1 мкл. Расчет хроматограмм проводился методом внутренней нормировки.

Переэтерификацию проводили в потоке инертного газа в четырехгорлой колбе, снабженной механической мешалкой и обратным холодильником, представляющим собой парциальный дефлегматор. Холодильник обогревали до температуры $70-80^{\circ}$, обеспечивающей выход паров метилового спирта. Конденсирующиеся в дефлегматоре пары высококипящего спирта стекали через гидрозатвор в колбу. Мольное соотношение ДМА и спирта составляло $1: 2,4$, количество тетрабутоксититана $-0,1 \%$ веса ДМА. В ходе реакции из колбы шприцем отбирали пробы в количестве $0,1-0,2$ мл, состав которых определяли непосредственно на газовом хроматографе. 


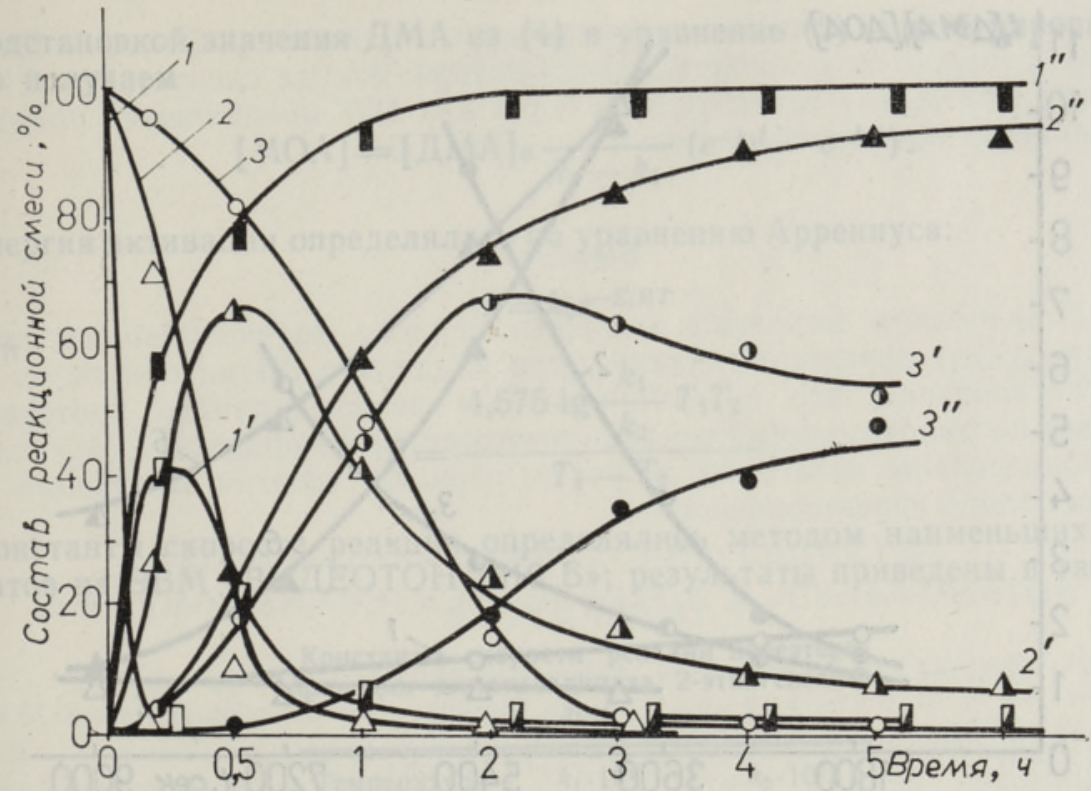

Рис. 1. Зависимость относительного содержания диметиладипата и продуктов его переэтерификации 2-этилгексанолом от температуры и времени реакции: 1 - при $180^{\circ} \mathrm{C} ; 2-$ при $140^{\circ} \mathrm{C} ; 3-$ при $120^{\circ} \mathrm{C} ; 1,2,3-$ [ДМА], $1^{\prime}, 2^{\prime}, 3^{\prime}-[$ МОА $], 1^{\prime \prime}, 2^{\prime \prime}, 3^{\prime \prime}-[$ [ДОА.

Катализатора $0,1 \%$.

Путем многократного введения в хроматограф смеси исходных компонентов и катализатора определено, что в течение анализов реакция переэтерификации не протекает. Наибольшее время удерживания имел катализатор (тетрабутоксититан), который удалялся из колонки продувкой при $230^{\circ}$.

На рис. 1 представлена зависимость относительного содержания диметиладипата (ДМА) и продуктов его переэтерификации 2-этилгексанолом (О) от температуры и времени реакции. Кинетические кривые имеют форму, характерную для последовательных реакций.

Переэтерификацию можно представить схемой:
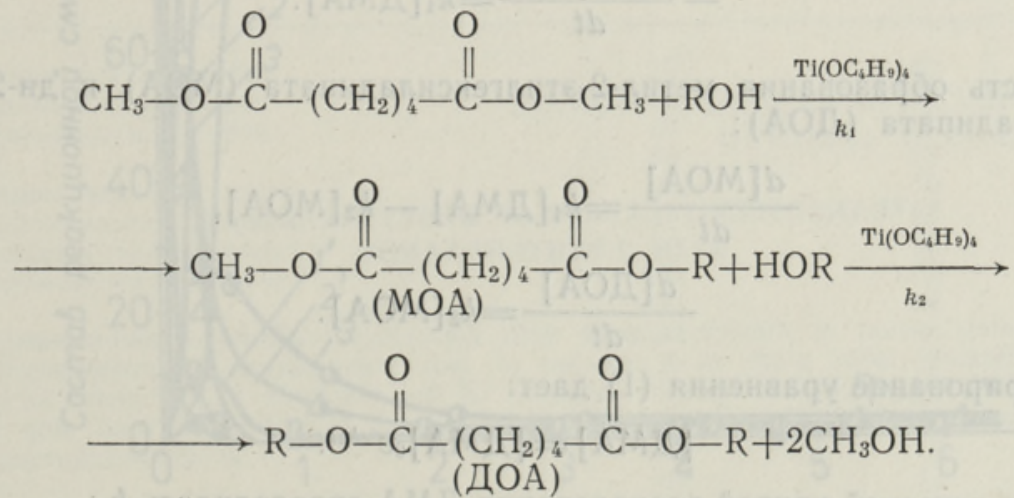

Порядок обеих реакций определен графически и методом подстановки. Графически получена линейная зависимость только для функций $\lg [$ ДМА $]=f(t)$ и $\lg [$ ДОА $]=f(t)$ (рис. 2$)$. 


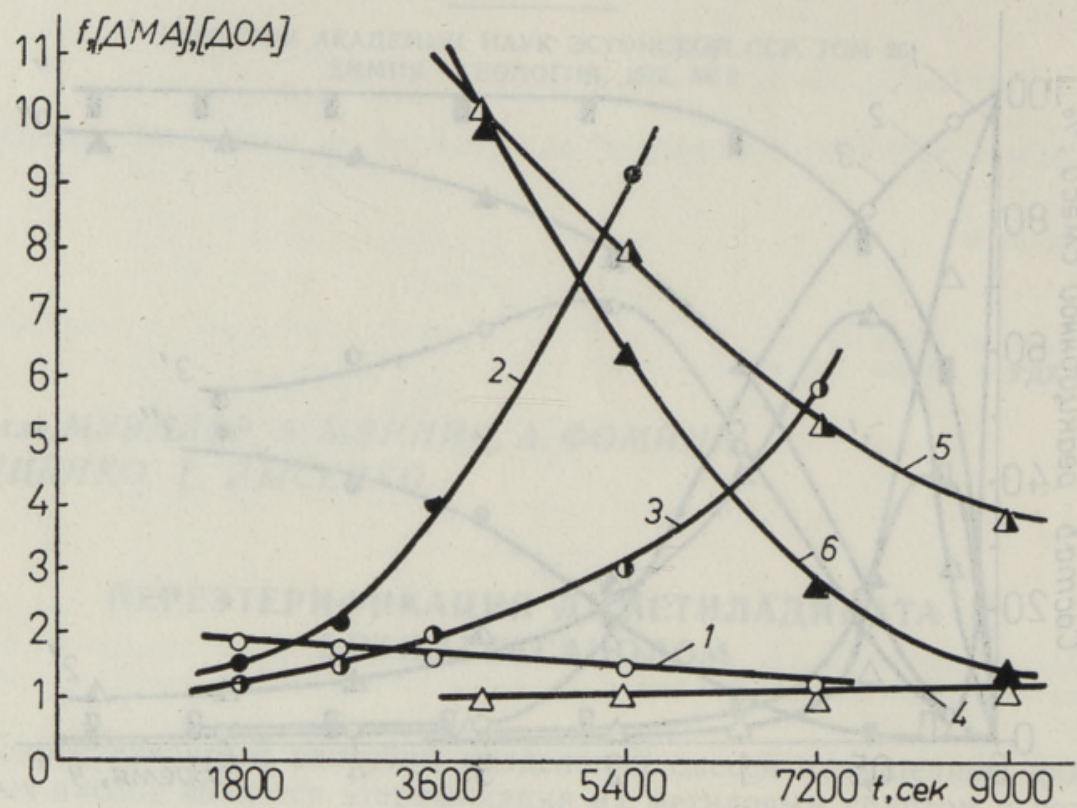

Рис. 2. Графическое определение порядка реакции переэтерификации ДМА 2-этилгексанолом при $120^{\circ} \mathrm{C}$.

$$
\begin{aligned}
& \left.1-\lg [\text { ДМА }]=f(t), \quad 2-\frac{1}{[Д М А ~}=f(t), \quad 3-\frac{1}{[Д М А ~}\right]^{2}=f(t), \\
& 4-\lg [\text { ДОА }]=f(t), \quad 5-\frac{1}{[Д О А ~}=f(t), \quad 6-\frac{1}{[Д О А]^{2}}=f(t) .
\end{aligned}
$$

Подстановка экспериментальных данных в кинетическое уравнение реакции первого порядка дала практически постоянные значения констант скорости.

Скорость исчезновения [ДМА] [3]:

$$
-\frac{d[\text { ДМА }]}{d t}=k_{1}[\text { ДМА }]
$$

Скорость образования метил-2-этилгексиладипата (MOA) и ди-2-этилгексиладипата (ДОА):

$$
\begin{gathered}
\frac{d[\mathrm{MOA}]}{d t}=k_{1}[\text { ДМА }]-k_{2}[\mathrm{MOA}], \\
\frac{d[\text { ДОА }]}{d t}=k_{2}[\mathrm{MOA}] .
\end{gathered}
$$

Интегрирование уравнения (1) дает:

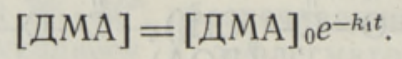

По кинетической кривой расходования ДМА определялась $k_{1}$ :

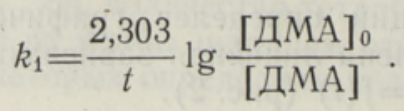


Подстановкой значения ДМА из (4) в уравнение (2) и интегрированием его получаем

$$
[\mathrm{MOA}]=[Д \mathrm{MA}]_{0} \frac{k_{1}}{k_{2}-k_{1}}\left(e^{-k_{1} t}-e^{-k_{2} t}\right)
$$

Энергия активации определялась по уравнению Аррениуса:

или

$$
k=k_{0} e^{-E / R T}
$$

$$
E=\frac{4,575 \lg \frac{k_{1}}{k_{2}} T_{1} T_{2}}{T_{1}-T_{2}} .
$$

\begin{tabular}{|c|c|c|}
\hline $\begin{array}{l}\text { Константы ск } \\
\text { фикации диме }\end{array}$ & $\begin{array}{l}\text { сти реа } \\
\text { адипата } \\
\text { лом }\end{array}$ & $\begin{array}{l}\text { переэт } \\
\text { илгекс }\end{array}$ \\
\hline $\begin{array}{l}\text { Температура } \\
\text { реакции, }{ }^{\circ} \mathrm{C}\end{array}$ & $\begin{array}{c}k_{1} \cdot 10^{4}, \\
\text { сек }^{-1}\end{array}$ & $\begin{array}{l}k_{2} \cdot 10^{4} \\
\text { сек }^{-1}\end{array}$ \\
\hline 120 & 2,25 & 0,52 \\
\hline 140 & 10,2 & 2,24 \\
\hline 180 & 62,6 & 19,5 \\
\hline
\end{tabular}

Константы скорости реакции определялись методом наименьших квадратов на ЭВМ «ВИДЕОТОН 1010 Б»; результаты приведены в таблице.

Была рассчитана энергия активации $E_{1}=20,3$ и $E_{2}=21,8 \kappa \kappa a \Omega$.

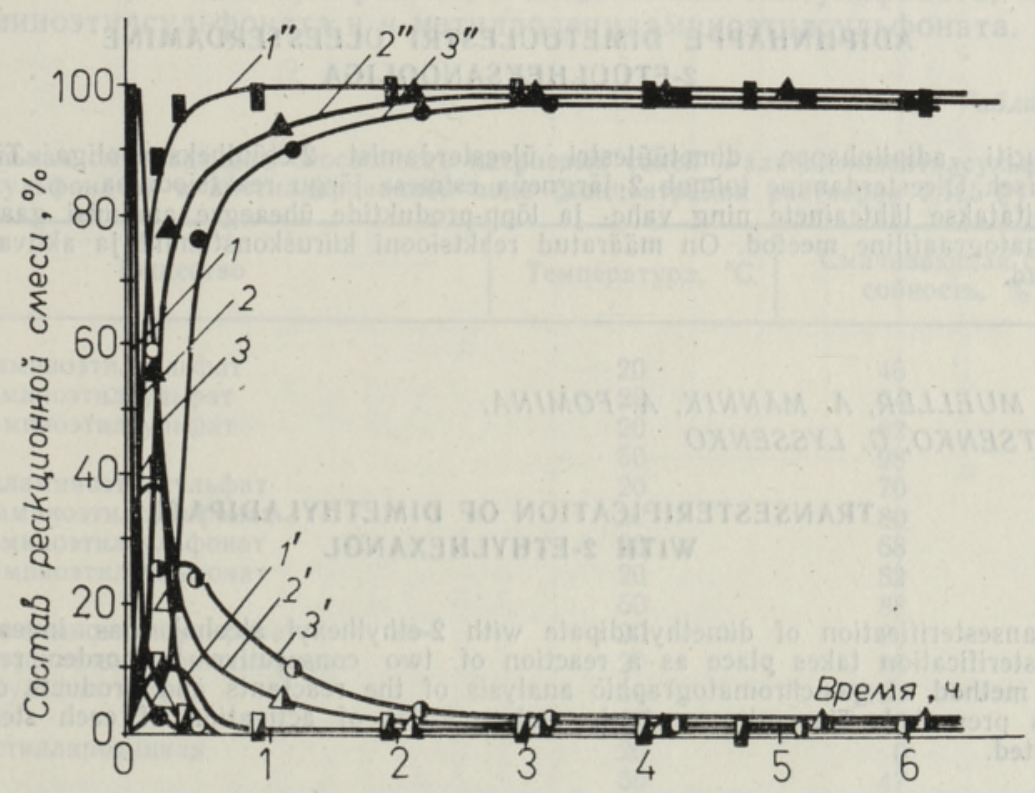

Рис. 3. Влияние количества катализатора на скорость реакции переэтерификации ДМА 2-этилгексанолом.

$1-0,5 \% \mathrm{Ti}\left(\mathrm{OC}_{4} \mathrm{H}_{9}\right)_{4}, \quad 2-0,1 \% \quad \mathrm{Ti}\left(\mathrm{OC}_{4} \mathrm{H}_{9}\right)_{4}, \quad 3-0,05 \% \quad \mathrm{Ti}\left(\mathrm{OC}_{4} \mathrm{H}_{9}\right)_{4} ;$

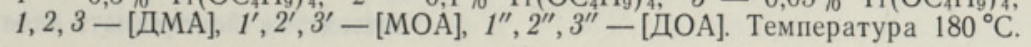


На рис. 3 приведена зависимость скорости переэтерификации ДМА 2-этилгексанолом от количества катализатора, откуда следует, что 0,1$0,5 \%$ (от веса ДМА) тетрабутоксититана при $180^{\circ}$ обеспечивает практически полную переэтерификацию в течение $1-2$ ч.

\section{Выводы}

1. Разработана методика непосредственного количественного анализа продуктов переэтерификации диметиладипата 2-этилгексанолом.

2. Установлено, что переэтерификация диметиладипата протекает через две последовательные реакции псевдопервого порядка.

3. Определены константы скорости реакции, энергия активации и условия полной переэтерификации.

\section{ЛИТЕРАТУ РА}

1. Kosuke, T o m it a, Hiroaki, I d a, Polymer, 1973, 14 (2), c. 55-60.

2. С ор ок и н М. Ф., Ч е б о т а р е в а Н. А., Тр. Московск. химико-технолог. ин-та, № 61, 103 (1969).

3. Л е й д л е р К., Кинетика органических реакций. М., 1966, с. 31-33.

$\begin{array}{cc}\text { Институт химии } & \text { Поступнла в редакцию } \\ \text { Академии наук Эстонской ССР } 1975\end{array}$

Sibille MUELLER, A. MÄNNIK, A. FOMINA,

A. KUTSENKO, G. LOSSENKO

\section{ADIPIINHAPPE DIMETUOLESTRI OLEESTERDAMINE 2-ETUOLHEKSANOOLIGA}

Uuriti adipiinhappe dimetüülestri üleesterdamist 2-etüülheksanooliga $\mathrm{Ti}(\mathrm{OBu})$ ، manulusel. Uleesterdamine toimub 2 järgneva esimese järgu reaktsioonina.

Esitatakse lähteainete ning vahe- ja lõpp-produktide üheaegse analüüsi gaasi-vedelikkromatograafiline meetod. On määratud reaktsiooni kiiruskonstandid ja aktivatsioonienergiad.

Sibille MUELLER, A. MÄNNIK, A. FOMINA,

A. KUTSENKO, G. LYSSENKO

\section{TRANSESTERIFICATION OF DIMETHYLADIPATE WITH 2-ETHYLHEXANOL}

Transesterification of dimethyladipate with 2-ethylhexyl alcohol was investigated. Transesterification takes place as a reaction of two consecutive first-order reactions.

A method of gas-chromatographic analysis of the reactants and products of reaction is presented. The rate constants and energies of activation of each step were calculated. 